\title{
PENGARUH MOTIVASI DAN LITERASI KEUANGAN TERHADAP MINAT BERINVESTASI PADA PASAR MODAL SYARIAH
}

(Studi Kasus Mahasiswa Universitas Muhammadiyah Sumatera Utara)

\author{
Wan Gustina Indah Sari ${ }^{{ }^{*}}$, Debbi Chyntia Ovami ${ }^{2}$ \\ ${ }^{1,2}$ Fakultas Ekonomi, Program Studi Akuntansi, UMN Al Washliyah, Medan, Indonesia \\ wangustinaindahsari@gmail.com
}

\begin{abstract}
ABSTRAK
Penelitian ini bertujuan untuk menguji dan menganalisis pengaruh motivasi dan literasi keuangan terhadap minat berinvestasi pada pasar modal syariah dengan studi kasus mahasiswa Universitas Muhammadiyah Sumatera Utara. Penelitian ini menggunakan data primer yaitu dengan menyebarkan kuesioner melalui google form. Responden dalam penelitian ini adalah mahasiswa/i S1 jurusan akuntansi stambuk 2018 dan 2019. Jumlah sampel dalam penelitian ini sebanyak 125 responden. Dari penyebaran kuesioner, sebanyak 102 responden (jumlah yang mengisi kuesioner) yang dapat diolah dan dianalisis dengan bantuan aplikasi computer SPSS Versi 25 for windows. Metode statistik yang digunakan untuk menguji hipotesis adalah analisis regresi linear berganda. Hasil penelitian menunjukkan bahwa variabel motivasi dan variabel literasi keuangan secara simultan berpengaruh terhadap variabel minat berinvestasi pada pasar modal syariah. Hal ini dibuktikan dari nilai $F_{\text {hitung }}$ sebesar 116,999 dan $F_{\text {tabel }}$ 3,09 dengan signifikansi 0,000. Hasil penelitian juga menunjukkan bahwa variabel motivasi dan literasi keuangan secara parsial berpengaruh terhadap minat berinvestasi. Hal ini dibuktikan dari nilai $t_{\text {hitung }}>t_{\text {tabel }}$ dimana nilai $t_{\text {hitung }}$ variabel motivasi sebesar 11,746 dan

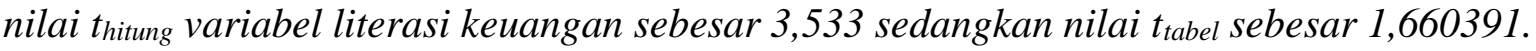

Kata kunci : Motivasi, Literasi Keuangan, Minat Berinvestasi.

\begin{abstract}
The objective of this research was to test and analyze the influence of motivation and financial literacy on investment interest in Islamic capital markets with case studies of students of Universitas Muhammadiyah Sumatera Utara. This research used primary data, namely by spreading questionnaires through google form. Respondents in this research were undergraduate students majoring in accounting in 2018 and 2019. The number of samples in this research was 125 respondents. From the spread of the questionnaire, as many as 102 respondents (the number who filled out the questionnaire) that can be processed and analyzed with the help of the SPSS Computer Application Version 25 for windows. The statistical method used to test hypotheses was multiple linear regression analysis. The results showed that motivational variables and financial literacy variables simultaneously affect the variables of interest in investing in Islamic capital markets. This was evidenced by the Fobserved value of 116,999 and Ftable 3.09 with a significance of 0.000. The results also showed that motivational variables and financial literacy partially affected investing interests. This was evidenced by the value of tobserved $>$ ttable where the value of tobserved motivation variable of 11,746 and the value of tobserved variable financial literacy of 3.533 while the value of ttable amounted to 1.660391 .
\end{abstract}

Keywords : Motivation, Financial Literacy, Investing Interests.

\section{PENDAHULUAN}


Perkembangan ekonomi saat ini akan menuntut individu untuk mengelola keuangan jangka pendek dan jangka panjangnya, seperti investasi. Investasi adalah penanaman modal pada satu atau lebih aset yang dimiliki, biasanya berjangka panjang, dengan harapan akan memperoleh keuntungan di masa yang akan datang (Sunariyah, 2011). Banyak orang sudah mencoba untuk berinvestasi, tetapi banyak juga yang mengalami kegagalan. Alasannya dikarenakan mereka tidak memiliki tujuan keuangan yang spesifik dan terukur dalam berinvestasi, sehingga menyebabkan dua hal, yaitu sulitnya mengetahui keberhasilan investasi dan kurangnya motivasi berinvestasi (Mike, 2014). Begitupun dengan mahasiswa yang akan memulai investasi, sebagai pemula, mahasiswa bisa memulai investasi dalam jumlah yang sedikit. Tetapi, walaupun bisa dilakukan dalam jumlah yang sedikit, bukan berarti hal ini dapat dilakukan dengan sesuka hati. Harus selalu mempertimbangkan berbagai faktor dan perhitungan yang benar sejak awal, sehingga hal ini dapat menghasilkan dan membawa banyak manfaat yang baik di bidang keuangan. Investasi dapat dilakukan melalui pasar modal. Pasar modal merupakan penghubung antara investor dan instansi pemerintah yang perlu memperdagangkan instrumen jangka panjang untuk memperoleh dana. Menurut (Widoatmodjo, 2012), pasar modal ialah pasar abstrak, yaitu memperdagangkan dana jangka panjang, dimana dana yang dikaitkan dengan investasi lebih dari satu tahun.

Indonesia merupakan negara dengan mayoritas muslim terbesar dunia. Untuk memenuhi kebutuhan umat Islam Indonesia yang ingin berinvestasi pada produk pasar modal yang sesuai dengan prinsip dasar syariah, maka pasar modal syariah adalah salah satu alternatif hingga saat ini. Secara umum kegiatan pasar modal syariah tidak berbeda dengan pasar modal konvensional, namun pasar modal syariah memiliki beberapa ciri khusus yaitu produk dan mekanisme transaksinya sesuai dengan kaidah syariah. Pasar modal syariah Indonesia ialah bagian dari industri keuangan syariah yang diatur oleh Otoritas Jasa Keuangan (OJK), khususnya direktorat pasar modal syariah.

Dalam rangka meningkatkan minat investasi di pasar modal, Bursa Efek Indonesia mengajak seluruh masyarakat Indonesia untuk berkontribusi melalui kampanye Yuk Nabung Saham. Tidak hanya itu, BEI juga bekerjasama dengan Perguruan Tinggi dan Perusahaan Sekuritas dalam membuka Galeri Investasi di Perguruan Tinggi yang ada di seluruh Indonesia dengan harapan Galeri Investasi tersebut dapat menjadi fasilitas yang bermanfaat untuk belajar menganalisa aktivitas perdagangan saham, diharapkan dapat menjadi jembatan menuju penguasaan ilmu pengetahuan beserta prakteknya di pasar modal. Universitas Muhammadiyah Sumatera Utara juga melakukan berbagai upaya dalam meningkatkan minat serta memperkenalkan lebih jauh lagi terkait investasi. Salah satunya ialah ikut berkontribusi dengan 
Prosiding The 1st National Conference on Applied Business, Education, \& Technology (NCABET)"

Unversitas Bina Bangsa 2021

DOI Article : 10.46306/ncabet.v1i1.7

BEI dan PT Phintraco Sekuritas membuka Galeri Investasi Syariah di lingkungan kampus pada tanggal 26 September 2017. Jumlah mahasiswa Universitas Muhammadiyah Sumatera Utara tahun 2018 sebanyak 16.662 dan jumlah mahasiswa yang membuka rekening investasi pada tahun 2018 sebanyak 161, apabila di persentasekan maka diperoleh sebesar 0,09\% mahasiswa telah membuka rekening investasi sejak berdirinya Galeri Investasi Syariah selama kurang lebih dalam 1 tahun. Hal ini menunjukkan bahwa minat berinvestasi di Pasar Modal Syariah sangat potensial untuk berkembang serta menjadi sarana dan prasarana bagi mahasiswa yang ingin memperluas pengetahuannya mengenai investasi.

Pemberian edukasi dan juga tersedianya fasilitas pendukung berupa Galeri Investasi ini terbilang masih belum cukup untuk sebagian mahasiswa jika tidak diimbangi dengan adanya motivasi dan finansial yang cukup dalam melakukan investasi. Motivasi menurut (Usman, 2013) yakni dorongan yang dimiliki seseorang dalam berbuat sesuatu, sebaliknya motif merupakan kebutuhan (need), kemauan (wish), dorongan (desire) ataupun impuls. Motivasi ialah dorongan yang dimiliki seseorang yang bisa memicu dalam melaksanakan tindakantindakan ataupun sesuatu yang jadi dasar ataupun alibi seseorang buat berperilaku ataupun melaksanakan sesuatu. Sebaliknya menurut (Fahriani, 2012) motivasi merupakan kondisi dalam pribadi seseorang yang mendorong kemauan individu dalam melaksanakan aktivitas aktivitas tertentu guna menggapai tujuan. Menurut penelitian dari (Wulandari, 2020) menunjukkan bahwa motivasi investasi berpengaruh positif dan signifikan terhadap minat investasi mahasiswa di pasar modal. Artinya jika mahasiswa memiliki motivasi investasi yang tinggi maka minat berinvestasi mahasiswa akan meningkat juga.

Tidak hanya motivasi, mahasiswa atau calon investor juga harus memiliki kemampuan dalam mengelola aset keuangannya. Tidak hanya mengelola aset yang ada, tetapi di samping itu, ada proses perencanaan untuk memperoleh aset tersebut. Tujuannya ialah untuk dapat mengelola aset keuangan secara efektif. Pengetahuan dan kemampuan untuk dapat mengelola asset keuangan biasa dikenal dengan istilah literasi keuangan. (Atkinson dan Messy, 2012) mengusulkan definisi literasi keuangan sebagai kombinasi dari kesadaran, pengetahuan, keterampilan, sikap dan perilaku yang diperlukan untuk membuat keputusan keuangan yang wajar dan pada akhirnya mencapai kesejahteraan keuangan seseorang. 


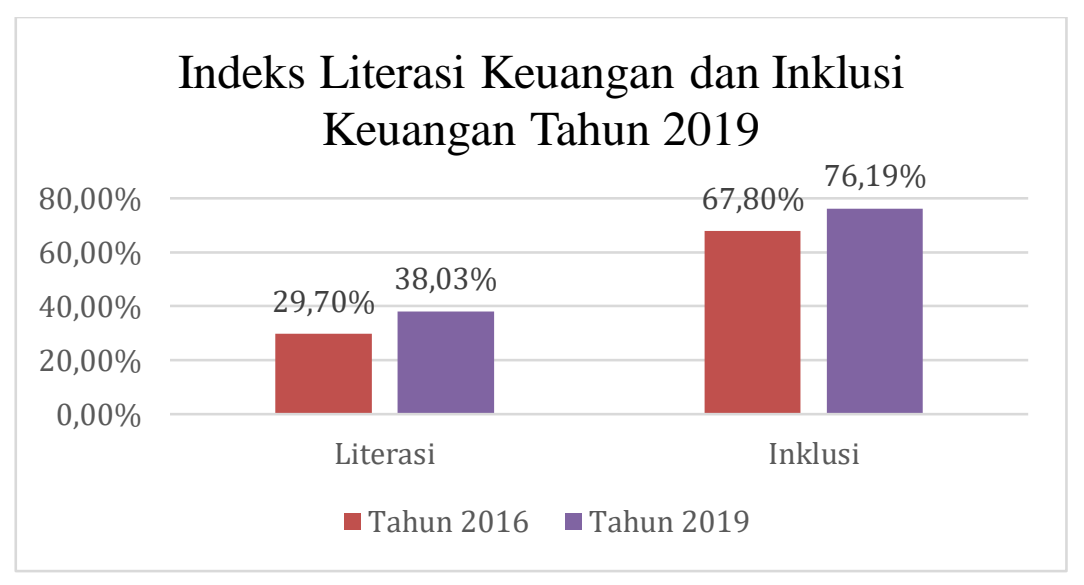

\section{Gambar 1.1 \\ Indeks Literasi Keuangan dan Inklusi Keuangan Nasional Tahun 2019 Sumber: $\underline{w w w . o j k . g o . i d}$}

Survei Nasional Literasi dan Inklusi Keuangan (SNLIK) dilakukan setiap 3 tahun sekali oleh Otoritas Jasa Keuangan (OJK). Tahun pertama dilakukan pada tahun 2013, tahun kedua pada 2016, dan tahun ketiga dilakukan tahun 2019. Dan data diatas merupakan hasil perbandingan dari survei ketiga dan kedua yang dilakukan oleh Otoritas Jasa Keuangan (OJK). Pada tahun 2019 menunjukkan indeks literasi keuangan mencapai 38,03\% dan indeks inklusi keuangan 76,19\%. Angka tersebut meningkat dibanding hasil survei OJK 2016 yaitu indeks literasi keuangan 29,7\% dan indeks inklusi keuangan 67,8\%. Dengan demikian selama 3 tahun terakhir terdapat peningkatan pemahaman keuangan (literasi) masyarakat sebesar 8,33\%, serta peningkatan akses terhadap produk dan layanan jasa keuangan (inklusi keuangan) sebesar 8,39\%. Survei SNLIK OJK 2019 ini mencakup 12.773 responden di 34 provinsi dan 67 kota/kabupaten dengan mempertimbangkan gender dan strata wilayah perkotaan/perdesaan. Di antara berbagai faktor dalam studi komprehensif, usia, pendidikan, jenis kelamin dan pekerjaan ditemukan sebagai faktor yang paling berpengaruh dalam peningkatan pemahaman literasi keuangan. (Lusardi dan Mitchell, 2011) melaporkan bahwa orang paruh baya memiliki pengetahuan keuangan yang lebih banyak daripada orang tua dan muda. Mereka juga menyatakan bahwa literasi keuangan pada perempuan lebih rendah daripada laki-laki. Sedangkan menurut (Bhushan, dkk, 2013) percaya bahwa usia tidak berpengaruh pada literasi keuangan. Mereka mengungkapkan fakta bahwa pekerjaan, pendidikan, jenis kelamin, dan tingkat pendapatan mempengaruhi literasi keuangan. Menurut penelitian dari (Alfia, dkk, 2020) mengatakan bahwa literasi keuangan memiliki pengaruh terhadap minat mahasiswa berinvestasi di pasar modal. Artinya bahwa semakin baik literasi keuangan mahasiswa maka semakin baik pula keputusan untuk melakukan investasi. 
Berdasarkan penjabaran diatas, penelitian ini bertujuan untuk melihat adanya motivasi dan juga literasi keuangan terhadap minat berinvestasi pada pasar modal syariah pada mahasiswa Universitas Muhammadiyah Sumatera Utara.

\section{METODE PENELITIAN}

Penelitian ini menggunakan jenis penelitian kuenatitatif dengan pendekatan asosiatif kausal. Menurut Sugiyono (2017: 57) pendekatan asosiatif ialah pendekatan yang menggambarkan dan menguji hipotesis hubungan dua variabel atau lebih. Populasi dalam penelitian ini mahasiswa Universitas Muhammadiyah Sumatera Utara prodi Akuntansi angkatan 2018 dan 2019 yang berjumlah 551 mahasiswa. Pengambilan sampel dilakukan berdasarkan ketentuan dari Hair et al (2014) dengan asumsi n (jumlah indikator) x 5. Adapun jumlah indikator dalam penelitian sebanyak 25 indikator x $5=125$ responden, dengan kriteria sebagai berikut:

1. Mahasiswa Universitas Muhammadiyah Sumatera Utara Program Strata 1 Prodi Akuntansi stambuk 2018 dan 2019.

2. Mahasiswa yang berumur 19-23 tahun.

Pengolahan data dibantu dengan menggunakan program Statistical Package For Social Science (SPSS) versi 25. Adapun teknik analisis data yang digunakan adalah regresi linear berganda dengan persamaan sebagai berikut:

$$
Y=\alpha+b 1 x 1+b 2 x 2+e
$$

Keterangan:

$\mathrm{Y}=$ Variabel dependen atau minat investasi.

$\mathrm{X}_{1}=$ Variabel independen atau motivasi investasi.

$\mathrm{X}_{2}=$ Variabel independen atau literasi keuangan.

a $=$ Konstanta.

$\mathrm{b}_{1} \mathrm{~b}_{2}=$ Koefisien linear berganda.

e $=$ Error.

Selain itu, terdapat beberapa uji lain yang digunakan dalam penelitian ini seperti:

a. Uji Kualitas Data

Terdapat 2 uji yang dilakukan dalam uji kualitas data yaitu uji validitas dan uji realibilitas. Menurut Sugiyono (2018: 173), validitas merupakan alat ukur yang dipakai untuk mendapatkan data (mengukur) itu valid. Uji realibilitas adalah sejauh mana hasil 
pengukuran dengan menggunakan objek yang sama, akan menghasilkan data yang sama (Sugiyono, 2018: 173).

b. Uji Asumsi Klasik

Dalam uji ini terdapat uji normalitas, uji multikolinearitas, dan uji heteroskedastisitas.

Uji normalitas digunakan untuk mengukur data yang berskala ordinal, interval, maupun rasio. Sedangkan uji multikolinearitas dilakukan untuk mengetahui apakah ditemukan adanya korelasi antara variabel bebas. Dan uji heteroskedastisitas dilakukan untuk menguji apakah dalam model regresi terjadi ketidaksamaan variabel dari residual satu pengamatan ke pengamatan yang lain.

c. Uji Hipotesis

Dalam menguji hipotesis diterima atau ditolak maka dapat dilakukan 3 uji seperti uji simultan F yang dilakukan untuk menguji apakah variabel independen berpengaruh terhadap variabel dependen. Uji statistik t yang digunakan untuk menguji pengaruh dari masing-masing variabel independen secara parsial terhadap variabel dependen. Dan uji koefisien determinasi $\left(\mathrm{R}^{2}\right)$ yang digunakan untuk memprediksi seberapa besar kontribusi pengaruh variabel independen terhadap variabel dependen.

\section{HASIL DAN PEMBAHASAN}

Berdasarkan perhitungan uji kualitas data maka dapat dinyatakan bahwa semua pernyataan atau indikator yang digunakan dalam penelitian ini valid dengan hasil $R_{\text {hitung }}>R_{\text {tabel }}$ yaitu 0,195 . Semua pernyataan atau indikator yang digunakan dalam penelitian ini juga reliable karena memiliki nilai Cornbach's Alpha >0,60.

Agar lebih mudah dipahami, berikut adalah hasil paparan uji yang disajikan dalam tabel dibawah ini:

Tabel 1. Uji Normalitas

\begin{tabular}{|c|c|c|}
\hline \multicolumn{3}{|c|}{ One-Sample Kolmogorov-Smirnov Test } \\
\hline & & $\begin{array}{l}\text { Unstandardized } \\
\text { Residual }\end{array}$ \\
\hline \multicolumn{2}{|l|}{$N$} & 102 \\
\hline \multirow[t]{2}{*}{ Normal Parameters ${ }^{a, b}$} & Mean & .0000000 \\
\hline & $\begin{array}{l}\text { Std. } \\
\text { Deviation }\end{array}$ & 2.77592562 \\
\hline \multirow{3}{*}{$\begin{array}{l}\text { Most Extreme } \\
\text { Differences }\end{array}$} & Absolute & .057 \\
\hline & Positive & .057 \\
\hline & Negative & -.048 \\
\hline \multicolumn{2}{|l|}{ Test Statistic } & .057 \\
\hline
\end{tabular}




\begin{tabular}{l|}
\hline Asymp. Sig. (2-tailed) \\
a. Test distribution is Normal. \\
b. Calculated from data.
\end{tabular}

Pada tabel 1 menunjukkan bahwa nilai signifikansi lebih besar dari 0,05 yaitu sebesar 0,200. Maka dapat disimpulkan bahwa nilai residual berdistribusi normal.

Tabel 2. Uji Multikolinearitas

\begin{tabular}{|c|c|c|c|c|c|c|c|}
\hline \multicolumn{8}{|c|}{ Coefficients $^{a}$} \\
\hline \multirow[b]{2}{*}{ Model } & \multicolumn{2}{|c|}{$\begin{array}{l}\text { Unstandardized } \\
\text { Coefficients }\end{array}$} & \multirow{2}{*}{$\begin{array}{c}\text { Standardiz } \\
\text { ed } \\
\text { Coefficient } \\
s \\
\\
\text { Beta }\end{array}$} & \multirow[b]{2}{*}{$T$} & \multirow[b]{2}{*}{ Sig. } & \multicolumn{2}{|c|}{$\begin{array}{c}\text { Collinearity } \\
\text { Statistics }\end{array}$} \\
\hline & B & $\begin{array}{l}\text { Std. } \\
\text { Error }\end{array}$ & & & & $\begin{array}{c}\text { Toleranc } \\
e\end{array}$ & $V I F$ \\
\hline (Constant) & -3.734 & 2.495 & & -1.497 & .138 & & \\
\hline Motivasi & .828 & .071 & .719 & 11.746 & .000 & .801 & 1.248 \\
\hline $\begin{array}{l}\text { Literasi } \\
\text { Keuangan }\end{array}$ & .228 & .064 & .216 & 3.533 & .001 & .801 & 1.248 \\
\hline
\end{tabular}

a. Dependent Variable: Minat Investasi

Pada tabel 4.32 diketahui bahwa nilai tolerance $0,801>0,1$ dan nilai VIF $1,248<10$. Maka dapat disimpulkan bahwa tidak terjadinya multikolinearitas antara variabel bebas.

Tabel 3. Uji Heteroskedastisitas

\begin{tabular}{|c|c|c|c|c|c|c|}
\hline \multicolumn{7}{|c|}{ Coefficients $^{a}$} \\
\hline & & \multicolumn{2}{|c|}{$\begin{array}{c}\text { Unstandardized } \\
\text { Coefficients }\end{array}$} & \multirow{2}{*}{$\begin{array}{c}\text { Standardized } \\
\text { Coefficients } \\
\text { Beta }\end{array}$} & \multirow[b]{2}{*}{$T$} & \multirow[b]{2}{*}{ Sig. } \\
\hline \multicolumn{2}{|c|}{ Model } & $\mathrm{B}$ & Std. Error & & & \\
\hline \multirow[t]{3}{*}{1} & (Constant) & 4.123 & 1.541 & & 2.676 & .009 \\
\hline & Motivasi & -.046 & .044 & -.119 & -1.067 & .289 \\
\hline & $\begin{array}{l}\text { Literasi } \\
\text { Keuangan }\end{array}$ & -.012 & .040 & -.033 & -.294 & .769 \\
\hline
\end{tabular}

a. Dependent Variable: Minat

Pada tabel 3 dapat diketahui bahwa nilai signifikansi variabel motivasi (X1) yaitu 0,289 $>0,05$ dan nilai signifikansi variabel literasi keuangan (X2) yaitu 0,769 > 0,05. Maka dapat diambil kesimpulan bahwa model regresi tidak terjadi heteroskedastisitas.

Tabel 4. Uji Simultan F

\begin{tabular}{|c|c|c|c|c|c|c|}
\hline \multicolumn{7}{|c|}{ ANOVA $^{a}$} \\
\hline & & $\begin{array}{l}\text { Sum of } \\
\text { Squares }\end{array}$ & Df & $\begin{array}{l}\text { Mean } \\
\text { Square }\end{array}$ & $\mathrm{F}$ & Sig. \\
\hline 1 & $\begin{array}{l}\text { Regressi } \\
\text { on }\end{array}$ & 1839.561 & 2 & 919.781 & $\begin{array}{r}116.99 \\
9\end{array}$ & $.000^{\mathrm{b}}$ \\
\hline
\end{tabular}




\begin{tabular}{|l|l|r|r|r|r|r|}
\hline Residual & 778.282 & 99 & 7.861 & & \\
\hline Total & 2617.843 & 101 & & & \\
\hline
\end{tabular}

a. Dependent Variable: Minat Investasi

b. Predictors: (Constant), Literasi Keuangan, Motivasi

Uji $F$ dapat dikatakan berpengaruh apabila $F_{\text {hitung }}>F_{\text {tabel }}$ dan sebaliknya jika $F_{\text {hitung }}<$ $F_{\text {tabel }}$ maka uji $\mathrm{F}$ tidak berpengaruh. Pada tabel 4 dapat diketahui bahwa nilai $F_{\text {hitung }}$ adalah sebesar 116,999. Hal ini menunjukkan bahwa 116,999 > 3,09. Maka dapat disimpulkan bahwa semua variabel $\mathrm{X}$ (motivasi dan literasi keuangan) secara bersama-sama (simultan) berpengaruh terhadap variabel Y (minat berinvestasi di pasar modal syariah).

Tabel 5. Uji Statistik t

\begin{tabular}{|l|l|r|r|r|r|r|}
\hline \multicolumn{7}{|c|}{ Coefficients $^{\mathbf{a}}$} \\
\hline \multirow{2}{*}{ Model } & \multicolumn{2}{|c|}{$\begin{array}{c}\text { Unstandardized } \\
\text { Coefficients }\end{array}$} & $\begin{array}{l}\text { Standardized } \\
\text { Coefficients }\end{array}$ & & \\
\cline { 2 - 7 } & \multicolumn{1}{|c|}{ B } & Std. Error & \multicolumn{1}{c|}{ Beta } & \multicolumn{1}{c|}{ T } & Sig. \\
\hline \multirow{3}{*}{1} & (Constant) & -3.734 & 2.495 & & -1.497 & .138 \\
\cline { 2 - 7 } & Motivasi & .828 & .071 & .719 & 11.746 & .000 \\
\cline { 2 - 7 } & $\begin{array}{l}\text { Literasi } \\
\text { Keuangan }\end{array}$ & .228 & .064 & .216 & 3.533 & .001 \\
\hline
\end{tabular}

a. Dependent Variable: Minat Investasi

Pada tabel 5 diketahui bahwa nilai thitung variabel motivasi sebesar 11,746 > 1,660391

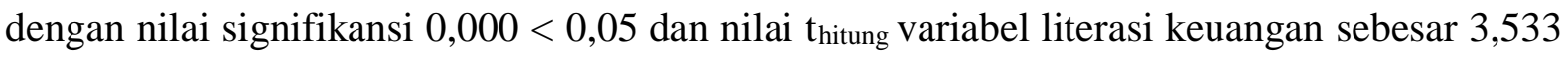
$>$ 1,660391 dengan nilai signifikansi 0,001 <0,05. Maka dapat disimpulkan bahwa variabel motivasi dan literasi keuangan berpengaruh positif dan signifikan terhadap minat berinvestasi.

Tabel 6. Uji Koefisien Determinasi $\left(\mathbf{R}^{2}\right)$

\begin{tabular}{|l|c|r|r|r|}
\hline \multicolumn{5}{|c|}{ Model Summary } \\
\hline Model & R & R Square & $\begin{array}{c}\text { Adjusted R } \\
\text { Square }\end{array}$ & $\begin{array}{l}\text { Std. Error of } \\
\text { the Estimate }\end{array}$ \\
\hline 1 & $.838^{\mathrm{a}}$ & .703 & .697 & 2.804 \\
\hline
\end{tabular}

a. Predictors: (Constant), Literasi Keuangan, Motivasi

Hasil pengujian koefisien determinasi dapat dilihat pada kolom Adjusted $R$ Square yaitu sebesar 0,69.7 artinya 69,7\% variabel minat berinvestasi pada pasar modal syariah dapat dijelaskan oleh variabel independen. Sedangkan sisanya sebesar 30,3\% dijelaskan oleh variabel-variabel lainnya seperti pengetahuan investasi, efikasi keuangan, dan preferensi resiko diluar dari model penelitian ini. 
Prosiding The 1st National Conference on Applied Business, Education, \& Technology (NCABET)"

Unversitas Bina Bangsa 2021

DOI Article : 10.46306/ncabet.v1il.7

Berdasarkan hasil penelitian menunjukkan bahwa variabel motivasi berpengaruh terhadap minat berinvestasi. Hal ini dibuktikan dengan nilai uji $t$ statistik dimana $t_{\text {hitung }}>t_{\text {tabel }}$ yaitu 11,746 > 1,660391 dan nilai signifikansinya 0,000 < 0,05 maka H1 diterima. Hal ini berarti bahwa motivasi yang dimiliki seorang mahasiswa akan membantu meningkatkan minat berinvestasi di pasar modal. Peningkatan tersebut ditandai dengan adanya tindakan-tindakan yang dilakukan mahasiswa dalam mencapai tujuannya. Hasil penelitian ini tidak sejalan dengan penelitian dari Hati \& Harefa (2019), berdasarkan hasil dari pengujian hipotesis menyatakan bahwa tidak terdapat pengaruh antara motivasi terhadap minat berinvestasi. Hal ini dikarenakan mahasiswa tidak terlalu memikirkan untuk memanfaatkan dana lebih yang dimiliki dari terpenuhinya kebutuhan hidup. Hasil penelitian ini juga sejalan dengan hasil penelitian dari Wulandari (2020), Isticharoh \& Kardoyo (2020), dan Shofwa (2017) yang mengatakan bahwa motivasi berpengaruh positif dan signifikan terhadap minat berinvestasi. Hasil penelitian ini tidak sejalan dengan penelitian dari Hati \& Harefa (2019), berdasarkan hasil dari pengujian hipotesis menyatakan bahwa tidak terdapat pengaruh antara motivasi terhadap minat berinvestasi. Hal ini dikarenakan mahasiswa tidak terlalu memikirkan untuk memanfaatkan dana lebih yang dimiliki dari terpenuhinya kebutuhan hidup.

Hasil analisis menunjukkan bahwa variabel literasi keuangan berpengaruh terhadap minat berinvestasi. Hal ini dibuktikan dengan nilai uji $t$ statistik dimana $t_{\text {hitung }}>t_{\text {tabel }}$ yaitu 3,533 $>$ 1,660391 dan nilai signifikansinya 0,001 < 0,05 maka H2 diterima. Hal ini menandakan bahwa semakin tinggi tingkat literasi keuangan seorang investor maka akan semakin baik perilaku keputusan investasi investor. Hasil penelitian ini juga sejalan dengan Alfia et al (2020) dan Shofwa (2017) yang menyatakan bahwa literasi keuangan berpengaruh positif terhadap minat mahasiswa berinvestasi di pasar modal. Hasil penelitian ini menolak hasil penelitian dari Junaidi et al (2019) dan Malik (2017) yang menyatakan bahwa literasi keuangan berpengaruh negatif dan tidak signifikan terhadap minat berinvestasi. Semakin rendahnya pemahaman seseorang dalam mengelola keuangannya maka akan semakin rendah pula minat untuk melakukan investasi.

Hasil analisis yang dilakukan melalui uji simultan F juga membuktikan bahwa variabel motivasi dan variabel literasi keuangan secara bersama-sama (simultan) berpengaruh terhadap variabel minat berinvestasi. Hal ini dapat dilihat dari nilai $F_{\text {hitung }}>F_{\text {tabel }}$ yaitu 116,999 $>$ 3,09.

\section{KESIMPULAN}


Berdasarkan hasil uji kualitas data, uji asumsi klasik, dan uji hipotesis yang telah dilakukan, maka dapat disimpulkan bahwa Motivasi dan Literasi Keuangan berpengaruh terhadap Minat Berinvestasi pada pasar modal syariah. Hal ini menandakan seseorang akan melakukan suatu tindakan terhadap suatu hal yang dapat membuatnya tertarik sehingga tanpa disadari orang tersebut termotivasi untuk mendapatkan apa yang diinginkannya. Motivasi yang dimiliki seorang mahasiswa akan membantu meningkatkan minat berinvestasi di pasar modal. Begitu juga dengan literasi keuangan mahasiswa, semakin baiknya pemahaman seorang individu dalam mengelola keuangannya, maka pemahaman tersebut akan mendorong adanya kemauan serta keinginan seseorang untuk berinvestasi, karena secara otomatis individu akan memahami bahwa ketika berinvestasi pasti akan mendapatkan pengembalian dan juga hasil.

Dari hasil penelitian ini, peneliti memberikan beberapa saran, diantaranya sebagai berikut:

1. Penelitian ini diharapkan dapat menjadi referensi bagi peneliti selanjutnya. Peneliti selanjutnya disarankan untuk menambah variabel lain agar dapat diketahui secara lebih luas lagi variabel apa saja yang mempengaruhi minat berinvestasi pada pasar modal syariah.

2. Peneliti selanjutnya juga disarankan untuk memperluas ruang lingkup responden.

\section{UCAPAN TERIMAKASIH}

Terimakasih kepada pihak-pihak yang telah membantu dalam penyelesaian penelitian ini, terutama kepada Universitas Muhammadiyah Sumatera Utara yang telah memberi izin kepada penulis untuk menjadikan Universitas Muhammadiyah Sumatera Utara sebagai lokasi penelitian penulis, dan juga kepada mahasiswa prodi Akuntansi Fakultas Ekonomi Universitas Muhammadiyah Sumatera Utara yang telah berkenan menjadi responden dalam penelitian ini. Adapun pihak-pihak lain yang terkait yang tidak bisa disebutkan satu per satu, penulis ucapkan terimakasih.

\section{DAFTAR PUSTAKA}

Alfia et al. 2020. "Pengaruh Pemahaman Investasi, Literasi Keuangan Dan Efikasi Keuangan Terhadap Minat Mahasiswa Berinvestasi Di Pasar Modal (Studi Empiris Mahasiswa Akuntansi Universitas Muhammadiyah Metro)". Jurnal SNPPM2. ISBN 978-62390328-5-2.

Atkinson \& Messy. 2012. "Measuring Financial Literacy: Result of the OECD / International Network on Financial Education (INFE) Pilot Study". OECD Working Papers on 
Prosiding The 1st National Conference on Applied Business, Education, \& Technology (NCABET)"

Unversitas Bina Bangsa 2021

DOI Article : 10.46306/ncabet.v1i1.7

Finance, Insurance and Private Pensions, No. 15. OECD Publishing. http://dx.doi.org/10.1787/5k9csfs90fr4-en

Bhushan, P.et al. 2013. "Financial Literacy and Its Determinants". International Journal of Engineering Business and Enterprise Application (IJEBEA), 4(2), March-May, 2013, pp. 155-160, ISSN:2279-0020 (Print) \& ISSN:2279-0039 (Online).

Fahriani, D. 2012. "Pengaruh Motivasi Terhadap Minat Mahasiswa Akuntansi Untuk Mengikuti Pendidikan Profesi Akuntansi (PPAK)”. Jurnal Ilmu \& Riset Akuntansi Vol. 1 No. 12 (2012).

Ghozali, Imam (2018). Aplikasi Analisis Multivariate dengan Program IBM SPSS 25. Badan Penerbit Universitas Diponegoro: Semarang.

Hair et al. 2014. A Primer On Partial Least Squares Structural Equation Modeling (PLS-SEM). United States of America : SAGE.

Hati, W. S. \& Harefa, S. W. 2019. “Analisis Faktor-Faktor Yang Mempengaruhi Minat Berinvestasi Di Pasar Modal Bagi Generasi Milenial (Studi Pada Mahasiswi Jurusan Manajemen Bisnis Politeknik Negeri Batam)". Journal of Business Administration, Vol 3, No 2, September 2019, hlm 281-295. e-ISSN:2548-9909.

Isticharoh \& Kardoyo. 2020. "Minat Investasi Diprediksi Dari Motivasi Diri, Pengetahuan Investasi, dan Teknologi Media Sosial". Jurnal Pendidikan Ekonomi, hlm 892-906. P:ISSN : 2252-6544. e-ISSN 2502-356X.

Junaidi et al. 2019. "Pengaruh Norma Subjektif, Motivasi Investasi, Pengetahuan Investasi, Persepsi Return dan Literasi Keuangan Terhadap Minat Mahasiswa Berinvestasi Saham di Pasar Modal (Studi Empiris Pada Mahasiswa Akuntansi FEB UNISMA dan UNIBRAW di Malang”. E-JRA, Vol. 08 No. 05 Agustus 2019.

Lusardi \& Mitchell. 2011. "Financial Literacy Around The World: An Overview". National Bureau of Economic Research Working Paper Series.1050 Massachusetts Avenue Cambridge, MA 02138. June 2011.

Malik, D. A. 2017. “Analisa Faktor-Faktor Yang Mempengaruhi Minat Masyarakat Berinvestasi di Pasar Modal Syariah Melalui Bursa Galeri UISI”. Jurnal Ekonomi dan Bisnis Islam.

Mike, R, Sutikno. 2014. Pentingnya Memiliki Tujuan Keuangan Dalam Berinvestasi. Diunduh pada tanggal 08 Desember 2020 dari http://mre.co.id/pentingnya-memiliki-tujuankeuangan-dalam berinvestasi/

Shofwa, Y. 2017. "Pengaruh Motivasi dan Literasi Keuangan Terhadap Minat Berinvestasi di Pasar Modal (Studi Kasus Mahasiswa Universitas Muhammadiyah Purwokerto)". Jurnal terbitan JPA, Vol. 18 No.2, Juli-Desember 2017. ISSN:1411-5875.

Sugiyono, 2018. Metode Penelitian Kuantitatif, Kualitatif, dan R\&D. Bandung: Penerbit Alfabeta.

Sunariyah, 2011. Pengantar Pengetahuan Pasar Modal. Edisi Keenam. Yogyakarta : Unit Penerbit dan Percetakan STIM YKPN. 
Usman, H. 2013. Manajemen Teori, Praktik, dan Riset Pendidikan. Jakarta: PT Bumi Aksara. Widoatmodjo, S. 2012. Cara Sehat Investasi di Pasar Modal. Edisi Revisi. Jakarta: PT. Jurnalindo Aksara Grafika.

Wulandari, A. 2020. "Pengaruh Motivasi Investasi Dan Pengetahuan Investasi Terhadap Minat Investasi Mahasiswa Di Pasar Modal (Studi Kasus Program Studi Manajemen Fakultas Ekonomi Dan Bisnis Universitas Ahmad Dahlan)". Jurnal Program Studi Manajemen S1. 